CURRENT OPINION IN INSECT SCIENCE

Insect Genomics Section

\title{
Applications of Genome Editing in Insects
}

William Reid, David A. O’Brochta*

*Corresponding Author:

Institute for Bioscience and Biotechnology Research

Department of Entomology

University of Maryland, College Park

9600 Gudelsky Drive

Rockville, MD 20850

240-314-6343

dobrocht@umd.edu 


\section{COIS 2015 DRAFT}

\section{Introduction}

Genome modification technologies have long been important tools for insect geneticistsbeginning with chemical mutagens and radiation[1]. Technologies for making planned and precise modifications of insect genomes have grown in number and sophistication beginning with transposon-based technologies in the early 1980s[2]. The first technology for editing insect genomes (targeted sequence modification or replacement) was described by Glooret al.and relied on double-strand DNA breakinduced homologous recombination/gene conversion to create new alleles of selected endogenous genes in Drosophila melanogaster(Table 1)[3]. Although effective, this technology wasinefficient and limited in utility because a transposon insertion in and excision from the gene to be editedwas usedto createdouble-stranded breaks in chromosomestostimulate homology directed repair. More sophisticated variations of this original method are available that have much improved efficiencies and take advantage of long running efforts to tag every gene in $D$. melanogaster with a transposon [4]. Rong and colleagues described gene-editing methods that were considerably more versatile than that of Gloor et al., allowing potentially any gene in the genome of $D$. melanogaster to be edited(Table 1$)[3,5,6]$. However, these systemsrelied ona number of specific transgenic lines of $D$. melanogasterand editingefforts involvedlarge genetic screens in order to find and recover the rare recombinants of interest.Consequently, similar systems in other insects have not been developed. 
More recently, advances in protein biochemistry and genetics have led to an understanding of the 'rules' governing the binding specificity of a number ofDNA-binding proteins such as meganucleases, zinc finger proteins and transcription activator-like effectors[7][8]. Some of these programmable DNA-binding proteins have been used to createDNA endonucleases whose site-specificity can be precisely controlled, allowing genome-editing technologies with broad applicability to be developed[7, 8].

DNA endonucleases with user-defined specificity (engineered nucleases) were first constructed from proteins containing multiple zinc-finger binding domains designed to recognize specific targetDNA sequences and attached to a DNA endonucleasesuch as Fok1 (Zinc Finger Nucleases, ZFNs) [9, 10]. Bibikova et al. demonstrated the efficacy ofZFNsfor editing genes in $D$. melanogasterhoweversignificant challenges in designing effective ZFNs as well as their cost of production constrain their use. In insects, with few exceptions, most studies involving the use of ZFNs have been technical in nature (Table 2) [11-23].

The transcription activator-like effectors (TALEs) from the plant pathogen Xanthomonasare another programmable DNA-binding protein system that has been exploited for the purposes of gene editing[24]. Designing TALEsissimpler than designing zinc-finger-containing proteins, howeverusing the TALE systemto create specific TALE-endonucleases (TALENs) still requires extensive gene-construction or synthesis. There have been a number of reports, mostly technical in nature, 


\section{COIS 2015 DRAFT}

demonstrating the functionality of TALENs in various insect species and the conditions under which they function best $[15,20,23,25-36]$.

\section{CRISPR/Cas}

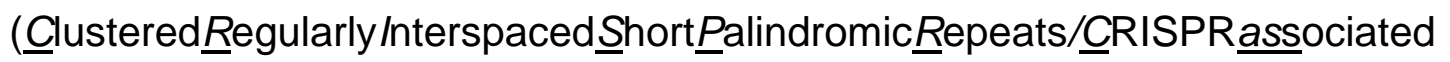
proteins)is an adaptive immune system found in bacteria and archaeathat enables these microbes to specifically recognize and degrade foreign intracellular DNA [37]. Cas9 is a DNA endonuclease associated with the CRISPR/Cas system found in Streptococcus pyogenes. The DNA sequence specificity of Cas9 is determinedby by small associated RNAs (crRNA and tracrRNA; in the lab these are combined to form a single RNA referred to as a guideRNA or gRNA)[37]. Unlike ZFNs and TALENs, Cas9 gene editing does not requirerepeatedly designing and expressing new Cas9 proteins, but instead onlyrequires producing short target-specific gRNAs that associate with Cas9to confer the desired site specificity [38].Despite only recently becoming available as a gene editing system, Cas9 is quickly being adopted by insect biologists although most uses in insects to date have been technical studies evaluating the performance characteristics of the system [20, 32, 35, 36, 39-67].

Here we focus on two aspects of applyinggene editing technologies in insects,1) possible applications of this technology to fundamental problems in insect biologyand practical problems caused by insects ofagricultural and public health importance, and 2) technical aspects of applying these technologies to insect genomes and our current understanding of 'best practices' for using the Cas9 system. 


\section{Applicationstolnsect Biology and Control}

Functional Genomics:Gene editing technologies hold great promise for those engaged in insect functional genomics studies because in their simplest form they are controllable mutagens. Mutant alleles and null alleles in particular provide opportunities for gaining insights into gene function that have usually only been available to those working on 'model' insects. Accessible geneediting capabilities based onengineeredendonucleases offer insect biologists new opportunities to create not just null alleles but almost any allele by using DNA sequence specific endonuclease activity to stimulate DNA repair mechanisms that result in indels at targeted locations or recombination and/or gene conversion at the target gene. Excellent recent examples of the fruitful use of gene editing technologies to address specific insect biological questions by creating null mutations (knockouts) includeLiesch et al., DeGennaro et al. and McMeniman et al.'s effective use of ZFNs to create null mutations in Aedes aegypti genes implicated in olfaction and host-finding $[17,18,22]$. Merlin et al. created null mutations in the type 2 vertebrate-like cryptochrome gene (CRY2) of Danaus plexippususing ZFNs, showing its essential role in the functioning of the circadian clock in this species [19].Daimon et al. and Enya et al. used TALENs to create null mutations in Bombyx morigenes involved in juvenile hormone synthesis/signaling and sterol metabolism, respectively, allowing them to make important insights into the development of these insects $[23,68]$.Zhang et al. and Daimon et al. also demonstrated how gene editing systems can be used to not only create heritable and vertically transmitted changes to genomes but also to conduct somatic mosaic analysis, a 
powerful approach for studying genes showing pleiotropy that has been largely limited in use to Drosophila melanogaster[23, 66, 69]. The high efficiency of contemporary engineered endonucleases can result in insects injected with the endonuclease during embryogenesis developing into insects containing a large number of cells with specific mutations and in some cases many cells can have both copies of the target gene mutated allowing meaningful analysis of phenotypes without screening for and establishing permanent lines of genetically modified insects, a challenging and laborious task with most insects.

Although creating various allelesis a fairly straightforward application of current gene editing technology (although not necessarily technically straightforward), when one considers ZFs, TALEs and certain variant forms of Cas9 (e.g. dCas9, a Cas9 variant without endonuclease activity) not just as potential mutagens but as tunable DNAbinding protein platforms upon which other functions can be attached, their potential as tools goes well beyond 'gene editing'. The potential for exploiting the site-specific DNA binding capabilities of these systems and exchanging endonuclease protein domainswith any one of a number of other protein domains with a variety of functions, such astranscription activation or repression, or chromatin modificationincreases the opportunities for insect biologists to exert control over insect gene expression and insect phenotypes[70].

Insect Control: Gene editing systems and, in particular, the Cas9 system because of its relative simplicity, affords insect scientists with new opportunities to realize longstanding 


\section{COIS 2015 DRAFT}

interestsin using genetics to manage insect pests[71]. Sterility-based systems such as the Sterile Insect Technique (SIT) often rely on specialized insect strains[72].For example,line of Medfly,Cerratitis capitata,currently mass-reared and used in SIT programsthroughout the world contains a reciprocal translocation and a temperaturesensitive lethal mutationthat result in female-specific embryonic lethality following a brief heat-shock of $34^{\circ} \mathrm{C}$, enabling the production and release of only sterilized males[73]. Gene editing technologies make the creation or re-creation of similar genotypes in other pest insect speciesfeasible and because these insects would not contain exogenous foreign DNAor transgenes, some contentious issues associated with the release of transgenic organisms might be avoided [74, 75].

There are longstanding interests, particularly among mosquito biologists, in altering the genetic composition of standing populations of mosquitoesto eliminate or modify phenotypes responsible for the mosquito's pest status[76]. Consequently, there areequally longstanding interests in 'gene drive' systems ie. genes, genetic elements or microbes that skew gene transmission patterns such that certain genotypes are overrepresented in the progeny of insects harboring these drive systems relative to what is expected if gene-transmission patterns strictly followed Mendelian expectations. Overrepresentation of certain genotypes in the progeny can result in the corresponding genotypes rapidly increasingin frequency[77]. Drive systems are envisioned that skew sex ratios to cause populations of pest insects to collapse, or to increase the frequency of individuals with genotypes that make the insects less of a pest (e.g. resistance to dengue virus or Plasmodium parasites) or easier to control (e.g. susceptible to 


\section{COIS 2015 DRAFT}

insecticide)[77].While many gene drive systems are known and some have been synthetically engineered, none have been useful for pest insect control because specific mechanisms causing gene drive are unknown or not amenable to manipulation, or because the drive systems are species specific[78-80]..

Homing endonuclease genes (HEGs), because of their potential to spread or 'drive' through populations, have been of great interest to insect biologists looking for facile gene drive systems[81]. Homing endonucleases, like ZFNs, TALENs and Cas9, causesequence-specific double-stranded breaks in DNA followed by homology-directed repair and gene-conversionresulting in a copy of the HEG being copied into the homologous chromosome lacking the HEG(Figure 1). Homing endonucleasesare powerful drive systemswhen the rates of DNA cutting and gene conversion are high and they have been shown to be functional in insects[77, 82]. Efforts to modify or tune theDNA-binding specificity and activity of homing endonucleaseshave met with some success[83, 84]. An engineered homing endonuclease (I-Ppol)known to cut a conserved sequence withina ribosomal RNA gene-cluster on the X-chromosome and carefully regulated so that it is only expressed during spermatogenesiswas inserted into an autosomeof Anopheles gambiaeusing transposon-based technology [84].. Sperm produced by this strain only contain $\mathrm{Y}$-chromosomes because the $\mathrm{X}$-chromosomes destined for half of the spermwere destroyed during gametogenesis when the homing endonuclease was expressed using a precisely regulated tissue-specific promoter. Consequently when males mate with wild-type females only male progeny are produced. This radical skewing of sex ratios destabilizeslaboratory populations of $A n$. 
gambiae, causing them to collapse[84]. Similar behavior under natural conditions could afford vector biologists with a powerful genetic tool to eradicate this deadly vector of human malaria parasites. While Galize et al. used a modified homing endonuclease, the readily tunable properties of Cas9, ZFNs, and TALENs allow similar systemsto be created for almost any insect, making this population suppression/elimination strategy widely applicable(Figure 1)[84]. The species specificity of this type of insect control strategy and its self-sustaining features could make this an attractive tool in some circumstances.

A Cas9-based gene drive system that behaves as a homing endonuclease was recently constructed in $D$. melanogasterresulting in the efficient conversion of insects heterozygous for a transgene expressing Cas9 and a gRNAinto homozygotes (Figure 1). Engineered endonuclease-based drive systems could be used to drive mutations into populations of pest species leading directly or indirectly to reduce population sizes. For example, mutations causing recessive semi lethality or any severe fitness cost could increase in frequency within populations provided the efficiency of the drive system is greater than the fitness costs associated with the mutations[85]. Genes affecting the immune system or perhaps genes involved in feeding or reproduction arepossibletarget genes[77]. The flexibility of contemporary engineered endonuclease systemsand the ease with which some can be designed and created makes the real challenge identifying and validating target genes and not in constructing a corresponding drive system to efficiently convert wild-type individuals to mutants. While there are numerous caveats associated with the use of synthetic drive systems, there is 
little doubt that engineered endonuclease-based gene drives are powerful and accessible tools for insect biologists to use against pest insect populations [85].

\section{Best Practices.}

Cas9-based genome editing technologies are simple and inexpensive to design and create, and consequently are experiencing a surge of use in insects. Successful insect genome editing using Cas9 requires careful attention to the design and assessment of gRNA, the delivery of Cas9 and gRNA, and the screening for and detection of insects with the mutation of interest. Here we briefly consider current practices used in insects and, where possible, identify 'best practices', however the immaturity of Cas9-based technologies and their limited use in insects makes identifying 'best practices' difficult. More valuable at this point is for potential users to be aware of the different approaches to deploying Cas9-based technologies rather than trying to make premature judgments concerning which is optimal or best.

gRNA Design and Assessment. Given the role gRNAs play in determining the specificity and efficacy of Cas9-based mutagenesis, their design is critically important. Universal gRNA-design parameters or rules do not exist but guidelines are emerging andthere are a number of on-line gRNA design tools to assist with the process[86-89].For example, guide RNAs with GC contents between $40 \%$ and $80 \%$ seem to work best. Cas 9 protein-DNA interactions appear limited to the trinucleotide Protospacer Adjacent Motif (PAM) and the +1 base of the gRNA sequences (Figure 2) andthe PAM affects the rate ofassociation of the gRNA and the DNA duplex resulting in the formation of an R loop. 
The gRNA stabilizes the R-loop, enabling Cas9-mediated cleavage of the DNA[87, 90, 91].Streptococcus pyogenes Cas9 shows a strong preference for GGG PAM sequences and gRNA with Gs at positions +1 and +2 (Figure 2) [91-93]. Variants of Streptococcus pyogenesCas9 have been created with altered preferences for PAM sequences and these promise to increase the accessibility of genomes to Cas9-based gene editing [94]. In Drosophila melanogaster gRNAs of 18-20 nucleotides work bestand must be a minimum of 17 nucleotides with the[53, 95]. Similarly, Kistler et al. found that gRNA lengths of 20 nucleotides work well in Aedes aegypti[64]. Off-target considerations are an additional concern during gRNA design and while off-target effects can be difficult to control, gRNA design can be facilitated knowing the degree to which base mismatches are tolerated within the gRNA. Fu et al. and Mali et al. found that up to 2-3 mismatches throughout the gRNA did not affect DNA cleavage specificity, while Ren et al. found that mismatches of 3 or more bases were not tolerated in $D$. melanogaster, particularly if the mismatcheswere present in the first 12 bases proximal to the PAM[53, 96, 97].

Delivery: Although insect scientists must rely on embryo microinjection technologies to deliver most genetic technologies to insects, when using the Cas9 system a number of options concerning howCas9 and gRNAs are delivered to the germ-lineorsoma of insects are available. These delivery options can impact the efficacy and efficiency of gene editing. Best practices remain unclear and results have varied from species to species. Options for delivering Cas9 include transiently expressing the Cas9 gene from plasmids injected into preblastoderm embryos, injecting in vitro-transcribed Cas9 mRNA or purified Cas9 protein into embryos and creating transgenic insects expressing Cas9 
in the germ-line (Table 2). Similarly, gRNAs can be delivered by injecting in vitrotranscribed gRNAs, injecting plasmids from which gRNAs are expressed and transgenic insects expressing gRNAtransgenes (Table 2).

Transgenic insects expressing Cas9 and gRNA transgenes in the germ-line have yielded high frequencies of germ-line mutations in $D$. melanogaster but this approach requires considerable preparation including the creation of the appropriate transgenic lines, a straightforward task with $D$. melanogasterbut much less so for most other insects [52]. Embryos from transgenic lines in which a Cas9 transgene is expressed in the germ-line can be injected with gRNAs to yield high rates of mutagenesis in these embryos, but this approach limits one to using insects with a particular genetic background and also requires the removal of the Cas9 transgene after mutagenesisby segregation or recombination. This approach has worked well with $D$. melanogaster where most genetic manipulations are relatively easy[52]. Expressing Cas9 transiently from plasmids injected into developing embryos is easy and inexpensive but has yielded mixed results. In Drosophila, this approach has been very successful, yielding high rates of mutagenesis and homology directed repair (knockin)[41, 48]. In Aedes aegypti, Donget al. reported being unable to recover mutants using this approach but was successful using in vitro-transcribed Cas9 mRNA and in vitro-transcribed gRNAs[61]. More recently, purified Cas9 protein has become available commercially and direct injection of a cocktail of gRNA and Cas9 protein into developing embryos has been highly effective[64]. Use of Cas9 protein has some advantages over using Cas9 mRNA including injection cocktails with lower viscosity, less sensitivity to degradation and the 
introduction of Cas9/gRNA complexes capable of immediately cleaving target DNA sequences. The concentration of Cas9 needs to be controlled since at high concentrations Cas9 maybe toxic[60, 98].

Reducing or eliminating the activity of various proteins involved in the non-homologous end-joining repair pathway such a Ligase IV or Ku80 has been shown to increase homology dependent DNA repair, improving rates at which sequences can be recombined into a target site (knock in)[16, 35]. Mutant lines of $D$. melanogasterlacking Ligase IV have been used as hosts for genome editing experiments and shown to improve rates of gene knock-in, while silencing Ligase IV gene expression by coinjecting Ligase IV dsRNA is also an option[16, 35]. The small molecule inhibitor of human Ligase IV, Scr7, has proven effective in increasing knock-in rates but whether it will inhibit insect Ligase IV is currently unknown[99, 100].

Screening and Detection: There are many options for detecting the presence of mutated cells and individuals that do not rely on visible phenotypes, and all rely on amplifying the target region after mutagenesis and looking for evidence of mutations. Methods include enzymatically detecting the presence of heteroduplex PCR products, loss of a restriction site, high resolution melt curve analysis and sequencing. All of these methods have proven effective but show varying degrees of sensitivity and ability to yield quantitative results. Finally, an ongoing challengeis to devise methods to genotype individual insects without killing them or disrupting their abilities to reproduce $[19,35,64]$. 


\section{Constraints and Limitations}

Gene editing technologies are capturing the imagination of insect scientists and for good reasons, but the widespread adoption and application of the technology very much depends on 1) the availability of technologies to deliver these systems to the desired cells at the desired times and, 2) the amenability of the target species to genetic analysis ie. controlled matings and screening. Delivering genetic technologies to the germ cells of insects relies almost exclusively on microinjection of preblastoderm embryos and the degree to which gene editing technologies are adopted will directly depend on the ease with which that problem can be solved. In addition, screening for and identifying insects with the desired genome modifications can require the use of molecular genotyping methods, adding another element of complexity that could limit in some cases the extent to which this technology will be adopted.

Finally, gene editing technologies are challenging existing paradigms and frameworks for considering genetically modified organisms in that, in many cases, the genomes subjected to gene editing contain no transgenes and are therefore not transgenic in the conventional sense[75, 101]. No gene vectors are involved, no foreign DNA is integrated and consequently insects and other organisms resulting from gene editing can appear no different from organisms arising from traditional genetic approaches to breeding and stock-development and, as a result,may be outside existing regulatory frameworks[75, 101]. In the United States and elsewhere, a reassessment of how genetically altered plants and animals are regulated is ongoing so that the regulatory 
process is based on the latest science and gene-edited organisms are thoughtfully considered before being created or released into the environment[74, 102, 103].

\section{Acknowledgements}

The following support to DAO'B is acknowledged: DEB1352978 (National Science Foundation), R01 Al099060 and R21 Al107230 (National Institutes of Health) 


\section{Figure Legends}

Figure 1. Engineered DNA endonuclease-based gene drive system. Any engineered DNA endonuclease system (HEGs, ZFNs, TALENs, Cas9) can be configured as a gene drive system (A). The endonuclease cassette (red) sits in chromosomal sequences (solid green lines) that flank the endonuclease's cleavage site (yellow arrow) so that when a plasmid containing this construct is introduced into cells it will result in the endonuclease cassette being inserted into the chromosome through homologous recombination (green dotted lines) (B). Cells heterozygous for the endonuclease cassette will become homozygous through targeted gene conversion (C). Efficient gene conversion will result in the rapid rise in the frequency of the endonuclease cassette and the corresponding insertion mutation within a population of cells or organisms ('gene drive').

Figure 2. Cas9 cleavage of DNA. The guide RNA (gRNA) associates with Cas9 (gray shape) and together they associate with double-stranded DNA at the PAM sequence (NGG). The PAM proximal and distal regions of the guide RNA form an R-loop. Guide RNA nucleotides 1-12 form the seed region that makes critical associations with the target DNA sequence. Cas9 cleavage of the DNA (green arrows) occurs between the third and fourth nucleotides proximal to the PAM. 


\section{REFERENCES CITED}

[1] Falk, R. Mutagenesis as a genetic research strategy. Genetics 2010; 185:11351139.

[2] Rubin, GM, Spradling, AC. Genetic transformation of Drosophila with transposable element vectors. Science 1982; 218:348-353.

[3] Gloor, GB, Nassif, NA, Johnson-Schlitz, DM, Preston, CR, Engels, WR. Targeted gene replacement in Drosophila via $P$ element-induced gap repair. Science 1991; 253:1110-1117.

[4] Vilain, S, Vanhauwaert, R, Maes, I, Schoovaerts, N, Zhou, LJ, Soukup, S, da Cunha, R, Lauwers, E, Fiers, M, Verstreken, P. Fast and efficient Drosophila melanogaster gene knock-uns using MiMIC transposons. G3-Genes Genomes Genetics 2014; 4:2381-2387.

[5] Rong, YS, Titen, SW, Xie, HB, Golic, MM, Bastiani, M, Bandyopadhyay, P, Olivera, BM, Brodsky, M, Rubin, GM, Golic, KG. Targeted mutagenesis by homologous recombination in D. melanogaster. Genes Dev. 2002; 16:1568-1581.

[6] Gong, WJ, Golic, KG. Ends-out, or replacement, gene targeting in Droso phila. Proc. Natl. Acad. Sci. U. S. A. 2003; 100:2556-2561.

*[7] Carroll, D. Genome Engineering with Targetable Nucleases. Annual Review of Biochemistry, Vol 83 2014; 83:409-439. This is an excellent overview of engineered endonucleases systems thta provides good background information and adequate details about mechanisms.

[8] Takeuchi, R, Choi, M, Stoddard, BL. Redesign of extensive protein,ÄìDNA interfaces of meganucleases using iterative cycles of in vitro compartmentalization. Proc. Natl. Acad. Sci. U. S. A. 2014; 111:4061-4066. 
[9] Kim, YG, Cha, J, Chandrasegaran, S. Hybrid restriction enzymes: Zinc finger

fusions to Fok I cleavage domain. Proc. Natl. Acad. Sci. U. S. A. 1996; 93:1156-1160.

[10] Bibikova, M, Carroll, D, Segal, DJ, Trautman, JK, Smith, J, Kim, YG,

Chandrasegaran, S. Stimulation of homologous recombination through targeted

cleavage by chimeric nucleases. Mol. Cell. Biol. 2001; 21:289-297.

[11] Bibikova, M, Golic, M, Golic, KG, Carroll, D. Targeted chromosomal cleavage and mutagenesis in Drosophila using zinc-finger nucleases. Genetics 2002;

161:1169-1175.

[12] Beumer, K, Bhattacharyya, G, Bibikova, M, Trautman, JK, Carroll, D. Efficient gene targeting in Drosophila with zinc-finger nucleases. Genetics 2006; 172:23912403.

[13] Beumer, KJ, Trautman, JK, Bozas, A, Liu, JL, Rutter, J, Gall, JG, Carroll, D. Efficient gene targeting in Drosophila by direct embryo injection with zinc-finger nucleases. Proc. Natl. Acad. Sci. U. S. A. 2008; 105:19821-19826.

[14] Takasu, Y, Kobayashi, I, Beumer, K, Uchino, K, Sezutsu, H, Sajwan, S, Carroll, D, Tamura, T, Zurovec, M. Targeted mutagenesis in the silkworm Bombyx mori using zinc finger nuclease mRNA injection. Insect Biochem. Mol. Biol. 2010; 40:759-765.

[15] Watanabe, T, Ochiai, H, Sakuma, T, Horch, HW, Hamaguchi, N, Nakamura, T, Bando, T, Ohuchi, H, Yamamoto, T, Noji, S et al.Non-transgenic genome modifications in a hemimetabolous insect using zinc-finger and TAL effector nucleases. Nat. Commun. 2012; 3.

*[16] Beumer, KJ, Trautman, JK, Mukherjee, K, Carroll, D. Donor DNA utilization during gene targeting with zinc-finger nucleases. G3-Genes Genomes Genetics 2013; 3:657-664. This paper clearly shows how manipulating the non-homologous end-joining pathway of insects can bias double-strand DNA break repair in favor of homology dependent repair as well as providing useful information onthe homology requirements for creating knock-in mutations. 
*[17] DeGennaro, M, McBride, CS, Seeholzer, L, Nakagawa, T, Dennis, EJ, Goldman, C, Jasinskiene, N, James, AA, Vosshall, LB. orco mutant mosquitoes lose strong preference for humans and are not repelled by volatile DEET. Nature 2013; 498:487-491. This is an early and good example of using engineered endonucleases as a mutagen in mosquitoes. It illustrates the value of having technology for creating null alleles.

[18] Liesch, J, Bellani, LL, Vosshall, LB. Functional and genetic characterization of neuropeptide Y-like receptors in Aedes aegypti. PLoS Negl. Trop. Dis. 2013; 7.

**[19] Merlin, C, Beaver, LE, Taylor, OR, Wolfe, SA, Reppert, SM. Efficient targeted mutagenesis in the monarch butterfly using zinc-finger nucleases. Genome Res. $2013 ; 23: 159-168$. This is a pioneering effort to bring genetic technologies to bare on a charismatic insect that has a complex and well known life history. This projects illustrates how even challenging insect systems are amenable to manipulation using existing engineered endonucleases.

[20] Daimon, T, Kiuchi, T, Takasu, Y. Recent progress in genome engineering techniques in the silkworm, Bombyx mori. Dev. Growth Differ. 2014; 56:14-25.

[21] Ma, SY, Shi, R, Wang, XG, Liu, YY, Chang, JS, Gao, J, Lu, W, Zhang, JD, Zhao, P, $\mathrm{Xia}$, QY. Genome editing of BmFib-H gene provides an empty Bombyx mori silk gland for a highly efficient bioreactor. Sci Rep 2014; 4.

[22] McMeniman, CJ, Corfas, RA, Matthews, BJ, Ritchie, SA, Vosshall, LB. Multimodal integration of carbon dioxide and other sensory cues drives mosquito attraction to humans. Cell 2014; 156:1060-1071.

**[23] Daimon, T, Uchibori, M, Nakao, H, Sezutsu, H, Shinoda, T. Knockout silkworms reveal a dispensable role for juvenile hormones in holometabolous life cycle. Proc. Natl. Acad. Sci. U. S. A. 2015; 112: E4226-E4235. Using engineered endonucleases to create null alleles for the purposes of exploring the reproductive physiology of insects is well illustrated in this paper. Importantly, the authors show how 
somatic mutations at the G0 stage can be an effective way by which genotypephenotype relationships can be explored.

[24] Bogdanove, AJ, Voytas, DF. TAL effectors: Customizable proteins for DNA targeting. Science 2011; 333:1843-1846.

[25] Liu, JY, Li, CQ, Yu, ZS, Huang, P, Wu, HG, Wei, CX, Zhu, NN, Shen, Y, Chen, YX, Zhang, B et al.Efficient and specific modifications of the Drosophila genome by means of an easy TALEN strategy. Journal of Genetics and Genomics 2012; 39:209215.

[26] Ma, SY, Zhang, SL, Wang, F, Liu, Y, Liu, YY, Xu, HF, Liu, C, Lin, Y, Zhao, P, Xia, QY. Highly efficient and Sspecific genome editing in silkworm using custom TALENS. PLOS ONE 2012; 7.

[27] Aryan, A, Anderson, MAE, Myles, KM, Adelman, ZN. TALEN-based gene disruption in the dengue vector Aedes aegypti. PLOS ONE 2013; 8.

[28] Sajwan, S, Takasu, Y, Tamura, T, Uchino, K, Sezutsu, H, Zurovec, M. Efficient disruption of endogenous Bombyx gene by TAL effector nucleases. Insect Biochem. Mol. Biol. 2013; 43:17-23.

[29] Smidler, AL, Terenzi, O, Soichot, J, Levashina, EA, Marois, E. Targeted mutagenesis in the malaria mosquito using TALE nucleases. PLOS ONE 2013; 8.

[30] Takasu, Y, Sajwan, S, Daimon, T, Osanai-Futahashi, M, Uchino, K, Sezutsu, H, Tamura, T, Zurovec, M. Efficient TALEN construction for Bombyx mori gene targeting. PLOS ONE 2013; 8.

[31] Wang, F, Ma, SY, Xu, HF, Duan, JP, Wang, YC, Ding, H, Liu, YY, Wang, XG, Zhao, $P, X i a, Q Y$. High-efficiency system for construction and evaluation of customized TALENs for silkworm genome editing. Mol. Genet. Genomics 2013; 288:683-690.

[32] Kondo, S. New horizons in genome engineering of Drosophila melanogaster. Genes Genet. Syst. 2014; 89:3-8. 


\section{COIS 2015 DRAFT}

[33] Wang, YJ, Nakagaki, M. Editing of the heavy chain gene of Bombyx mori using transcription activator like effector nucleases. Biochem. Biophys. Res. Commun. 2014; 450:184-188.

*[34] Xu, J, Wang, Y, Li, Z, Ling, L, Zeng, B, James, AA, Tan, A, Huang, Y.

Transcription activator-like effector nuclease (TALEN)-mediated female-specific sterility in the silkworm, Bombyx mori. Insect Mol. Biol. 2014; 23:800-807. The authors illustrate how the binary nature of TALENs cculd be used to create sterile female insects. The strategy is straightforward and nicely illustrates the power of this technology in creating genotypes and phenotypes that are of potential significance to efforts to use genetics as a pest control tool.

[35] Basu, S, Aryan, A, Overcash, JM, Samuel, GH, Anderson, MAE, Dahlem, TJ, Myles, KM, Adelman, ZN. Silencing of end-joining repair for efficient site-specific gene insertion after TALEN/CRISPR mutagenesis in Aedes aegypti. Proc. Natl. Acad. Sci. U. S. A. 2015; 112:4038-4043.

[36] Lee, HB, Sebo, ZL, Peng, Y, Guo, Y. An optimized TALEN application for mutagenesis and screening in Drosophila melanogaster. Cellular Logistics 2015; 5:e1023423.

[37] Sorek, R, Lawrence, CM, Wiedenheft, B. CRISPR-mediated adaptive immune systems in bacteria and archaea. Annu. Rev. Biochem. 2013; 82:237-266.

[38] Jinek, M, Chylinski, K, Fonfara, I, Hauer, M, Doudna, JA, Charpentier, E. A programmable dual-RNA-guided DNA endonuclease in adaptive bacterial immunity. Science 2012; 337:816-821.

[39] Baena-Lopez, LA, Alexandre, C, Mitchell, A, Pasakarnis, L, Vincent, JP. Accelerated homologous recombination and subsequent genome modification in Drosophila. Development 2013; 140:4818-4825. 
[40] Bassett, AR, Tibbit, C, Ponting, CP, Liu, JL. Highly efficient targeted mutagenesis of Drosophila with the CRISPR/Cas9 system. Cell Reports 2013; 4:220-228.

[41] Gratz, SJ, Cummings, AM, Nguyen, JN, Hamm, DC, Donohue, LK, Harrison, MM, Wildonger, J, O'Connor-Giles, KM. Genome engineering of Drosophila with the CRISPR RNA-guided Cas9 nuclease. Genetics 2013; 194:1029-1035.

[42] Gratz, SJ, Wildonger, J, Harrison, MM, O'Connor-Giles, KM. CRISPR/Cas9mediated genome engineering and the promise of designer flies on demand. Fly (Austin) 2013; 7:249-255.

[43] Kondo, S, Ueda, R. Highly improved gene targeting by germline-specific Cas9 expression in Drosophila. Genetics 2013; 195:715-721.

[44] Ren, XJ, Sun, J, Housden, BE, Hu, YH, Roesel, C, Lin, SL, Liu, LP, Yang, ZH, Mao, DC, Sun, LZ et al.Optimized gene editing technology for Drosophila melanogaster using germ line-specific Cas9. Proc. Natl. Acad. Sci. U. S. A. 2013; 110:1901219017.

[45] Yu, ZS, Ren, MD, Wang, ZX, Zhang, B, Rong, YKS, Jiao, RJ, Gao, GJ. Highly efficient genome modifications mediated by CRISPR/Cas9 in Drosophila. Genetics 2013; 195:289-291.

[46] Bassett, AR, Liu, JL. CRISPR/Cas9 and genome editing in Drosophila. Journal of Genetics and Genomics 2014; 41:7-19.

[47] Böttcher, R, Hollmann, M, Merk, K, Nitschko, V, Obermaier, C, Philippou-Massier, J, Wieland, I, Gaul, U, Forstemann, K. Efficient chromosomal gene modification with CRISPR/cas9 and PCR-based homologous recombination donors in cultured Drosophila cells. Nucleic Acids Res. 2014; 42:e89.

[48] Gokcezade, J, Sienski, G, Duchek, P. Efficient CRISPR/Cas9 plasmids for rapid and versatile genome editing in Drosophila. G3-Genes Genomes Genetics 2014; 4:2279-2282. 
[49] Gratz, SJ, Ukken, FP, Rubinstein, CD, Thiede, G, Donohue, LK, Cummings, AM, O'Connor-Giles, KM. Highly specific and efficient CRISPR/Cas9-catalyzed homology-directed repair in Drosophila. Genetics 2014; 196:961-971.

[50] Lin, SC, Chang, YY, Chan, CC. Strategies for gene disruption in Drosophila. Cell and Bioscience 2014; 4.

[51] Ma, SY, Chang, JS, Wang, XG, Liu, YY, Zhang, JD, Lu, W, Gao, J, Shi, R, Zhao, P, Xia, QY. CRISPR/Cas9 mediated multiplex genome editing and heritable mutagenesis of BmKu70 in Bombyx mori. Sci Rep 2014; 4:4489.

[52] Port, F, Chen, HM, Lee, T, Bullock, SL. Optimized CRISPR/Cas tools for efficient germline and somatic genome engineering in Drosophila. Proc. Natl. Acad. Sci. U. S. A. 2014; 111:E2967-E2976.

[53] Ren, XJ, Yang, ZH, Xu, J, Sun, J, Mao, DC, Hu, YH, Yang, SJ, Qiao, HH, Wang, X, $\mathrm{Hu}, \mathrm{Q}$ et al.Enhanced specificity and efficiency of the CRISPR/Cas9 system with optimized sgRNA parameters in Drosophila. Cell Reports 2014; 9:1151-1162.

[54] Ren, XJ, Yang, ZH, Mao, DC, Chang, Z, Qiao, HH, Wang, X, Sun, J, Hu, Q, Cui, Y, Liu, LP et al.Performance of the Cas9 Nickase System in Drosophila melanogaster. G3-Genes Genomes Genetics 2014; 4:1955-1962.

[55] Sebo, ZL, Lee, HB, Peng, Y, Guo, Y. A simplified and efficient germline-specific CRISPR/Cas9 system for Drosophila genomic engineering. Fly (Austin) 2014; 8:5257.

[56] Wei, W, Xin, HH, Roy, B, Dai, JB, Miao, YG, Gao, GJ. Heritable genome editing with CRISPR/Cas9 in the silkworm, Bombyx mori. PLoS ONE 2014; 9:e101210.

[57] Xue, ZY, Ren, MD, Wu, MH, Dai, JB, Rong, YKS, Gao, GJ. Efficient gene knockout and knock-in with yransgenic Cas9 in Drosophila. G3-Genes Genomes Genetics 2014; 4:925-929. 
[58] Xue, ZY, Wu, MH, Wen, KJ, Ren, MD, Long, L, Zhang, XD, Gao, G. CRISPR/Cas9 mediates efficient conditional mutagenesis in Drosophila. G3-Genes Genomes Genetics 2014; 4:2167-2173.

[59] Zhang, X, Koolhaas, WH, Schnorrer, F. A versatile two-step CRISPR- and RMCE-based strategy for efficient genome engineering in Drosophila. G3-Genes Genomes Genetics 2014; 4:2409-2418.

[60] Ablain, J, Durand, EM, Yang, S, Zhou, Y, Zon, LI. A CRISPR/Cas9 vector system for tissue-specific gene disruption in Zebrafish. Dev. Cell 2015; 32:756-764.

[61] Dong, SZ, Lin, JY, Held, NL, Clem, RJ, Passarelli, AL, Franz, AWE. Heritable CRISPR/Cas9-mediated genome editing in the yellow fever mosquito, Aedes aegypti. PLOS ONE 2015; 10:e0122353.

**[62] Gantz, VM, Bier, E. The mutagenic chain reaction: A method for converting heterozygous to homozygous mutations. Science 2015; 348:442-444. Although pretentious in its claim of novelty, this paper nicely illustrates how engineered endonucleases, in this case the Cas9 system, can be configured to behave as a homing endonuclease, a class of genes with well characterized properties including the ability to 'drive' through populations with non-Mendelian dynamics.

[63] Gilles, AF, Schinko, JB, Averof, M. Efficient CRISPR-mediated gene targeting and transgene replacement in the beetle Tribolium castaneum. Development 2015:2832-2839.

**[64] Kistler, KE, Vosshall, LB, Matthews, BJ. Genome engineering with CRISPR-Cas9 in the mosquito Aedes aegypti. Cell Reports 2015; 11:51-60. The authors explore Cas9 mutagenesis in mosquitoes and identify important approaches and parameters that should be considered. Their clear and detailed methods provide an excellent starting point for anyone wishing to initiate Cas9-based mutagenesis in insects.

**[65] Port, F, Muschalik, N, Bullock, SL. Systematic evaluation of Drosophila CRISPR tools reveals safe and robust alternatives to autonomous gene drives in basic 
research. G3: Genes|Genomes|Genetics 2015; 5:1493-1502. The authors compare the various resources available for performing Cas9-based mutagenesis in $D$. melanogaster in an effort to compare their effectiveness and efficiency and to decide on best practices. Although concerned with $D$. melanogaster, the findings and observations reported here are broadly helpful.

[66] Zhang, Z, Aslam, AFM, Liu, X, Li, M, Huang, Y, Tan, A. Functional analysis of Bombyx Wnt1 during embryogenesis using the CRISPR/Cas9 system. J. Insect Physiol. 2015; 79:73-79.

[67] Li, X, Fan, D, Zhang, W, Liu, G, Zhang, L, Zhao, L, Fang, X, Chen, L, Dong, Y, Chen, $Y$ et al.Outbred genome sequencing and CRISPR/Cas9 gene editing in butterflies. Nat. Commun. 2015; 6.

[68] Enya, S, Daimon, T, Igarashi, F, Kataoka, H, Uchibori, M, Sezutsu, H, Shinoda, T, Niwa, R. The silkworm glutathione S-transferase gene noppera-bo is required for ecdysteroid biosynthesis and larval development. Insect Biochem. Mol. Biol. 2015; 61:1-7.

[69] Griffin, R, Binari, R, Perrimon, N. Genetic odyssey to generate marked clones in Drosophila mosaics. Proc. Natl. Acad. Sci. U. S. A. 2014; 111:4756-4763.

[70] Lin, S, Ewen-Campen, B, Ni, X, Housden, BE, Perrimon, N. In vivo transcriptional activation using CRISPR-Cas9 in Drosophila. Genetics 2015.

[71] Davidson, G. Genetic control of insect pests. London: Academic Press, Inc. ; 1974.

[72] Dyck, VA, Hendrichs, J, Robinson, AS. Sterile Insect Technique: Principles and practice in area-wide integrated pest management. In: 1. Springer Netherlands; 2005. pp. XIV, 787.

[73] Franz, G. Genetic sexing strains in mediterranean fruit fly, an example for other species amenable to large-scale rearing for the sterile insect technique. In: 
Sterile Insect Technique. Edited by: Dyck VA, Hendrichs J, Robinson AS. Netherlands: Springer; 2005. pp. 427-451.

[74] Servick, K. U.S. to review agricultural biotech regulations: New gene-editing methods challenge old framework. Science 2015; 349:131.

[75] Waltz, E. Tiptoeing around transgenics. Nat Biotech 2012; 30:215-217.

[76] Craig, GB. Prospects for vector control through manipulation of populations. Bull. World Health Organization 1963; 29:89-97.

[77] Burt, A. Heritable strategies for controlling insect vectors of disease. Philosophical Transactions of the Royal Society B-Biological Sciences 2014; 369:20130432.

[78] Hay, BA, Chen, C-H, Ward, CM, Huang, H, Su, JT, Guo, M. Engineering the genomes of wild insect populations: Challenges, and opportunities provided by synthetic Medea selfish genetic elements. J. Insect Physiol. 2010; 56:1402-1413.

[79] Akbari, OS, Matzen, KD, Marshall, JM, Huang, HX, Ward, CM, Hay, BA. A Synthetic Gene Drive System for Local, Reversible Modification and Suppression of Insect Populations. Curr. Biol. 2013; 23:671-677.

[80] Akbari, OS, Chen, C-H, Marshall, JM, Huang, H, Antoshechkin, I, Hay, BA. Novel Synthetic Medea Selfish Genetic Elements Drive Population Replacement in Drosophila; a Theoretical Exploration of Medea-Dependent Population Suppression. ACS Synthetic Biology 2014; 3:915-928.

[81] Burt, A. Site-specific selfish genes as tools for the control and genetic engineering of natural populations. Proc. Roy. Soc. Lond. 2003; 270:921-928.

[82] Chan, YS, Naujoks, DA, Huen, DS, Russell, S. Insect population control by homing endonuclease-based gene drive: An evaluation in Drosophila melanogaster. Genetics 2011; 188:33-44. 
[83] Doyon, JB, Pattanayak, V, Meyer, CB, Liu, DR. Directed evolution and substrate specificity profile of homing endonuclease I-scel. J. Am. Chem. Soc. 2006; 128:2477-2484.

**[84] Galizi, R, Doyle, LA, Menichelli, M, Bernardini, F, Deredec, A, Burt, A, Stoddard, BL, Windbichler, N, Crisanti, A. A synthetic sex ratio distortion system for the control of the human malaria mosquito. Nat. Commun. 2014; 5:3977. This is an exciting application of engineered endonucleases combined with precise tissue- and temporal-specific gene expression resulting in a powerful sex ratio distortion system in Anopheles gambiae.Males carrying the homing endonuclease gene will produce predominantly $\mathrm{Y}$ chromosome-bearing sperm and male progeny.

[85] Unckless, RL, Messer, PW, Connallon, T, Clark, AG. Modeling the manipulation of natural populations by the mutagenic chain reaction. Genetics 2015.

[86] Ma, M, Ye, AY, Zheng, W, Kong, L. A guide RNA sequence design platform for the CRISPR/Cas9 system for model organism genomes. Biomed Research International 2013:270805.

[87] Doench, JG, Hartenian, E, Graham, DB, Tothova, Z, Hegde, M, Smith, I, Sullender, $M$, Ebert, BL, Xavier, RJ, Root, DE. Rational design of highly active sgRNAs for CRISPR-Cas9-mediated gene inactivation. Nat. Biotechnol. 2014; 32:1262-1267.

[88] Heigwer, F, Kerr, G, Boutros, M. E-CRISP: Fast CRISPR target site identification. Nat. Methods 2014; 11:122-124.

*[89] Montague, TG, Cruz, JM, Gagnon, JA, Church, GM, Valen, E. CHOPCHOP: a CRISPR/Cas9 and TALEN web tool for genome editing. Nucleic Acids Res. 2014; 42:W401-W407. One of the better-documented and user friendly online tools for designing, evaluating and choosing guide RNAs for use with Cas9.

[90] Szczelkun, MD, Tikhomirova, MS, Sinkunas, T, Gasiunas, G, Karvelis, T, Pschera, P, Siksnys, V, Seidel, R. Direct observation of R-loop formation by single RNA- 
guided Cas9 and Cascade effector complexes. Proc. Natl. Acad. Sci. U. S. A. 2014; 111:9798-9803.

[91] Wang, T, Wei, JJ, Sabatini, DM, Lander, ES. Genetic screens in human cells using the CRISPR-Cas9 system. Science 2014; 343:80-84.

[92] Chari, R, Mali, P, Moosburner, M, Church, GM. Unraveling CRISPR-Cas9 genome engineering parameters via a library-on-library approach. Nat Meth 2015; 12:823-826.

[93] Farboud, B, Meyer, BJ. Dramatic enhancement of genome editing by CRISPR/Cas9 through improved guide RNA design. Genetics 2015; 199:959-971.

*[94] Kleinstiver, BP, Prew, MS, Tsai, SQ, Topkar, VV, Nguyen, NT, Zheng, Z, Gonzales, APW, Li, Z, Peterson, RT, Yeh, J-RJ et al.Engineered CRISPR-Cas9 nucleases with altered PAM specificities. Nature 2015; 523:481-485. Cas9 can be used to mutagenize only the fraction of the genome associated with the canonical PAM site, but in this paper altered Cas9 proteins are created with new PAM requirements, enabling a larger fraction of genomes to be accessible to Cas9 mutagenesis.

[95] Fu, YF, Sander, JD, Reyon, D, Cascio, VM, Joung, JK. Improving CRISPR-Cas nuclease specificity using truncated guide RNAs. Nat. Biotechnol. 2014; 32:279284.

[96] Fu, YF, Foden, JA, Khayter, C, Maeder, ML, Reyon, D, Joung, JK, Sander, JD. High-frequency off-target mutagenesis induced by CRISPR-Cas nucleases in human cells. Nat. Biotechnol. 2013; 31:822-826.

[97] Mali, P, Yang, LH, Esvelt, KM, Aach, J, Guell, M, DiCarlo, JE, Norville, JE, Church, GM. RNA-guided human genome engineering via Cas9. Science 2013; 339:823-826.

[98] Jiang, W, Brueggeman, AJ, Horken, KM, Plucinak, TM, Weeks, DP. Successful Transient Expression of Cas 9 and Single Guide RNA Genes in Chlamydomonas reinhardtii. Eukaryot. Cell 2014; 13:1465-1469. 


\section{COIS 2015 DRAFT}

[99] Chu, VT, Weber, T, Wefers, B, Wurst, W, Sander, S, Rajewsky, K, Kuhn, R. Increasing the efficiency of homology-directed repair for CRISPR-Cas9-induced precise gene editing in mammalian cells. Nat Biotech 2015; 33:543-548.

[100] Maruyama, T, Dougan, SK, Truttmann, MC, Bilate, AM, Ingram, JR, Ploegh, HL. Increasing the efficiency of precise genome editing with CRISPR-Cas9 by inhibition of nonhomologous end joining. Nat Biotech 2015; 33:538-542.

*[101] Araki, M, Nojima, K, Ishii, T. Caution required for handling genome editing technology. Trends Biotechnol. 2014; 32:234-237. This paper suscinctly discusses the implications of current gene editing technologies on existing governmental regulatory systems and illustrates how current technology has outpaced existing regulations.

**[102] Webber, BL, Raghu, S, Edwards, OR. Opinion: Is CRISPR-based gene drive a biocontrol silver bullet or global conservation threat? Proceedings of the National Academy of Sciences 2015; 34:10565-10567. This is a thoughtful argument for using approaches to risk assessment developed for classical biological control as a framework for considering the development and release of gene drive-based technologies for the purposes of erradicating populations of invasive species.

[103] Akbari, BOS, Bellen, HJ, Bier, E, Bullock, SL, Burt, A, Church, GM, Cook, KR, Duchek, $\mathrm{P}$, Edwards, OR, Esvelt, KM et al.Safeguarding gene drive experiments in the laboratory. Science 2015. 


\section{Endonuclease cassette}

\section{Cas9}

sgRNA $\rightarrow$

homing endonuclease

TALEN left

TALEN right $\longrightarrow$

ZFN left

ZFN right

B

\section{Endonuclease cassette}<smiles>CC1C[CH]C1</smiles>

Endonuclease cassette

\section{Endonuclease cassette}

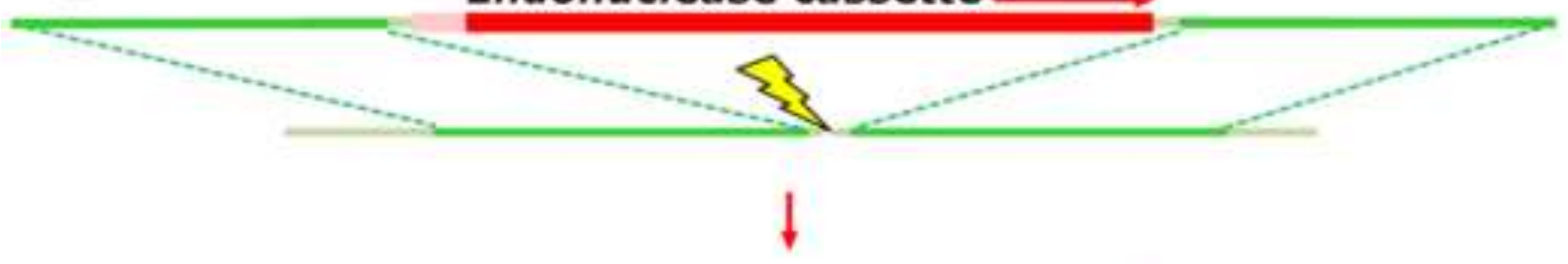

Endonuclease cassette 


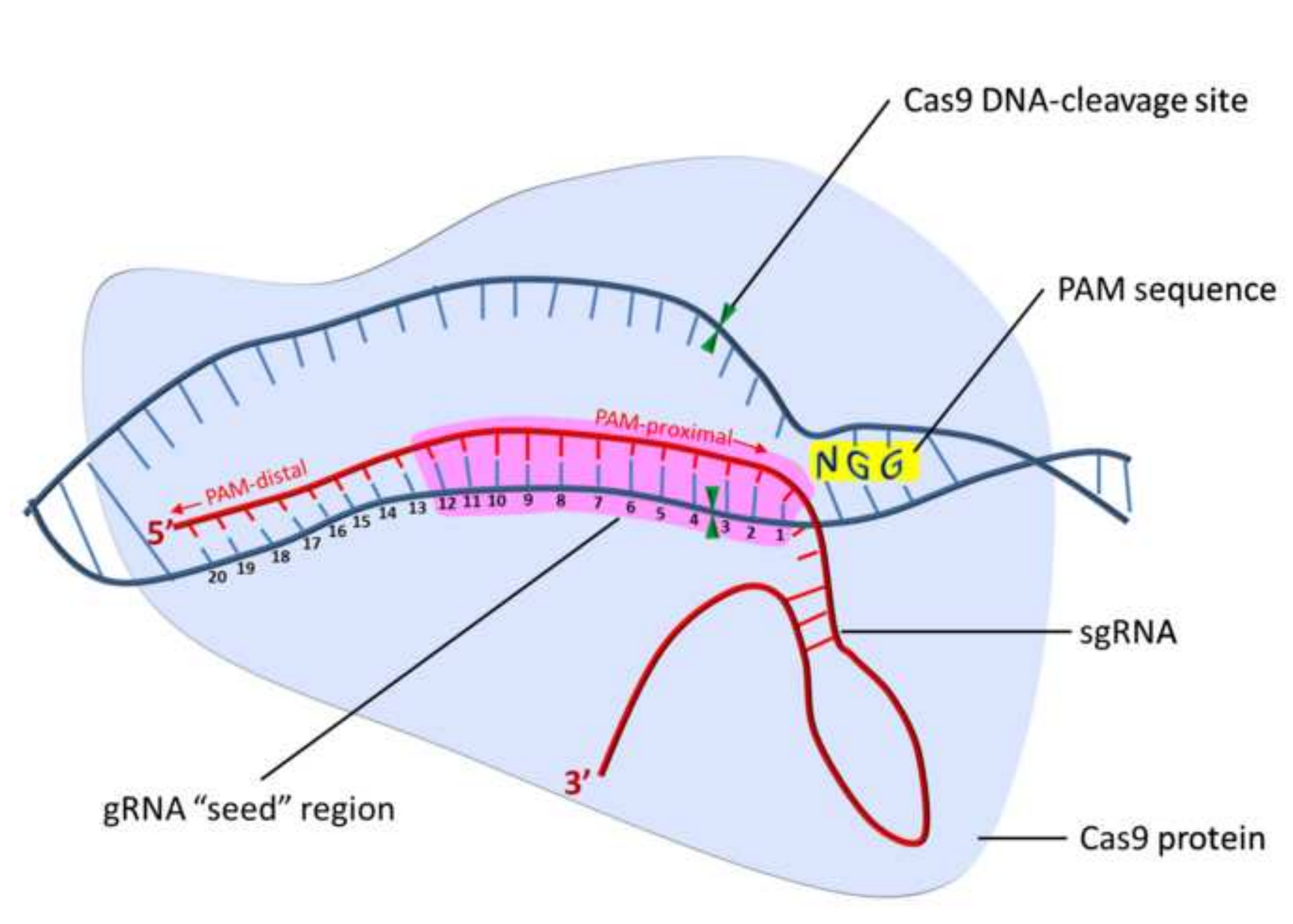

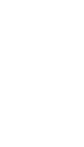


Table 1. Insect Genome Editing

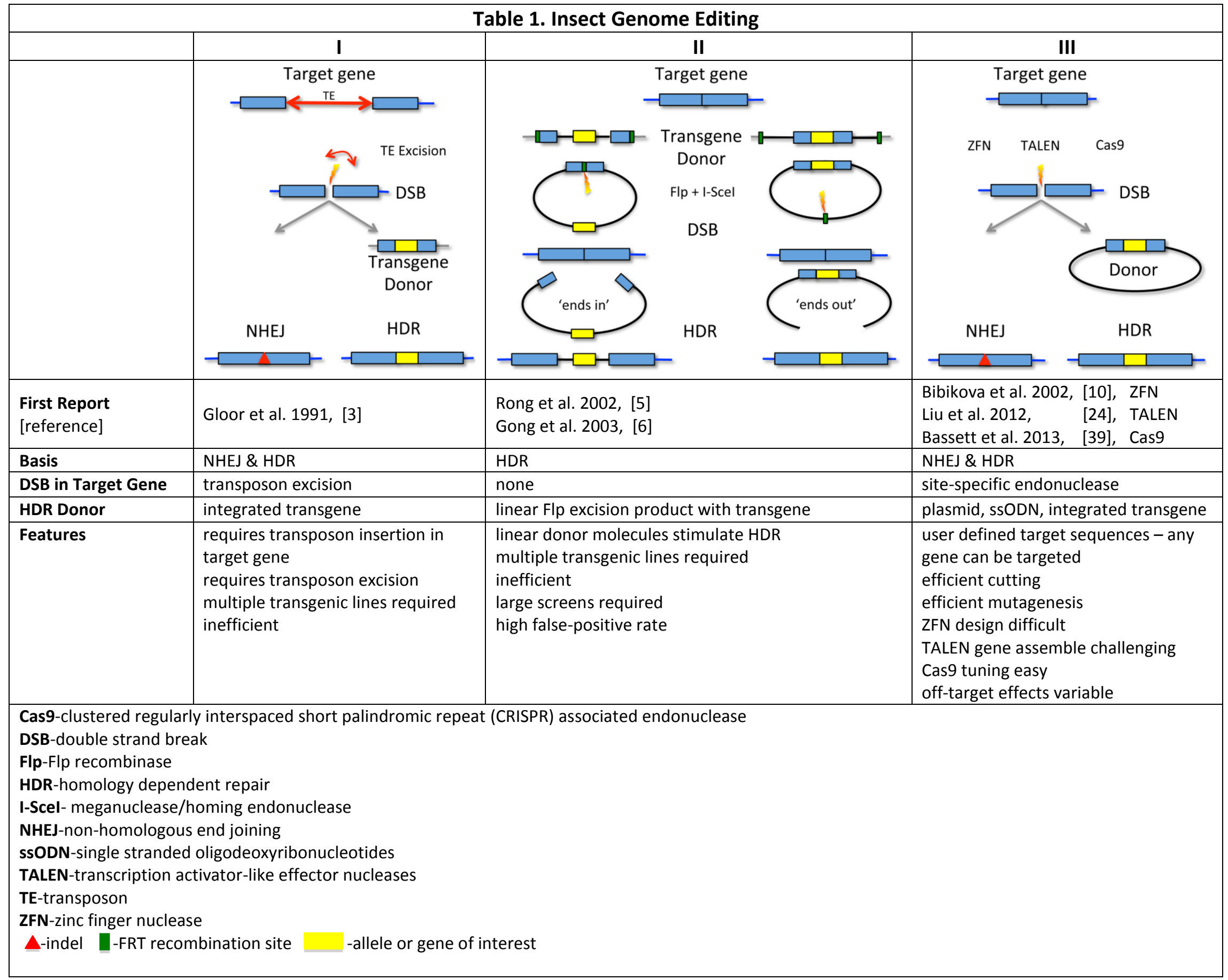




\begin{tabular}{|c|c|c|c|c|c|c|c|c|c|}
\hline Insect & Author & Date & Ref & Sys & Delivery & Cells & Gene & Mut & Results \\
\hline \multicolumn{10}{|l|}{ Lepidoptera } \\
\hline Danaus plexippus & Merlin & 2013 & 19 & Z & mRNA & G & Dpcry2 & KO & $\begin{array}{l}44 \%-88 \% \mathrm{~S} \\
50 \% \mathrm{G} \\
39.2 \%-50 \% \mathrm{G} 1\end{array}$ \\
\hline Papilio xuthus & $\mathrm{Li}$ & 2015 & 67 & C & mRNA & S & $A b d-B$, ebony, $f z$ & KO & $16 \%-95 \% \mathrm{~S}$ \\
\hline \multirow{14}{*}{ Bombyx mori } & Takasu & 2010 & 14 & Z & mRNA & $S, G$ & BmBLOS2 & KO & $0.28 \% G 1$ \\
\hline & $\mathrm{Ma}$ & 2012 & 26 & $\mathrm{~T}$ & mRNA & $S, G$ & BmBLOS2 & KO & $\begin{array}{l}15 \%-31 \% G \\
0.4 \%-61 \% G 1\end{array}$ \\
\hline & Sajwan & 2013 & 28 & $\mathrm{~T}$ & mRNA & $S, G$ & BmBLOS2 & KO & $\begin{array}{l}2.8 \%-7.7 \% G \\
0.05 \%-0.69 \% \text { G1 }\end{array}$ \\
\hline & Takasu & 2013 & 30 & $\mathrm{~T}$ & mRNA & $S, G$ & BmBLOS2; Bm-re & KO & $\begin{array}{l}9.5 \%-100 \% \mathrm{G} \\
0.7 \%-50 \% \mathrm{G} 1\end{array}$ \\
\hline & Wang & 2013 & 31 & $\mathrm{~T}$ & mRNA & S & plasmid & KO & NR \\
\hline & Daimon & 2014 & 20 & $\mathrm{Z}, \mathrm{T}, \mathrm{C}$ & mRNA,gRNA & $S, G$ & BmBLOS2 & KO KI & $\begin{array}{l}\mathrm{C}: 0 \%-58 \% \text { KO } \\
\mathrm{C}: 0 \%-25 \% \mathrm{G} \mathrm{KO} \\
\mathrm{C}: 0.46 \% \mathrm{G} 1 \mathrm{KO} \\
\mathrm{C}: 9.4 \% \mathrm{~S} \mathrm{KI} \\
\mathrm{C}: 0.008 \% \mathrm{G} 1 \mathrm{KI}\end{array}$ \\
\hline & $\mathrm{Ma}$ & 2014 & 21 & Z & mRNA & G & $B m F i b-H$ & KO & $65.79 \%-73.47 \% \mathrm{G}$ \\
\hline & $\mathrm{Ma}$ & 2014 & 51 & C & plasmid & $\mathrm{G}, \mathrm{S}$ & BmKu70, Bm702 & KO KI & $1 \% G 1$ \\
\hline & Wang & 2014 & 33 & $\mathrm{~T}$ & mRNA & $\mathrm{G}$ & Bm heavy chain & KO & $8.2 \% G$ \\
\hline & Wei & 2014 & 56 & $\mathrm{C}$ & mRNA,gRNA & $S, G$ & $\begin{array}{c}\text { Bm-ok, BmKMO, BmTH, } \\
\text { Bmtan }\end{array}$ & KO & $\begin{array}{l}16 \%-35 \% \mathrm{~S} \\
28.6 \% \mathrm{G} 1\end{array}$ \\
\hline & $\mathrm{Xu}$ & 2014 & 34 & $\mathrm{~T}$ & transgene & S & Bm-doublesex & KO & $100 \% \mathrm{~S}$ \\
\hline & Daimon & 2015 & 23 & $\mathrm{~T}$ & mRNA & $S, G$ & $\begin{array}{c}\text { Bm JHAMT, BmMet1, } \\
\text { BmMet2, broad }\end{array}$ & KO & NR \\
\hline & Enya & 2015 & 68 & $\mathrm{~T}$ & mRNA & G & nobo- $B m$ & KO & NR \\
\hline & Zhang & 2015 & 66 & C & mRNA,gRNA & s & Bm-Wnt1 & KO & $18.8 \%-81.9 \mathrm{~S}$ \\
\hline \multicolumn{10}{|c|}{$\begin{array}{l}\text { Ref-Reference } \\
\text { Sys- Endonuclease System: Z-ZFN; T-TALEN, C-Cas9, } C^{n} \text {-Cas9 with single-strand endonuclease activity (nickase), dC-dead Cas9 (no endonuclease activity) } \\
\text { Delivery: } m R N A \text {-injected in vitro transcribed message RNA; gRNA-injected in vitro transcribed guide RNA; plasmid-transient expression of system components from injected } \\
\text { plasmids; transgene-integrated transgenes containing system components; protein-purified Cas9 } \\
\text { Cells: S-somatic; G-germ-line; G1-progeny from G } \\
\text { Mut-Mutation: KO-knockout; KI-knockin, TA-transcription activation }\end{array}$} \\
\hline
\end{tabular}




\begin{tabular}{|c|c|c|c|c|c|c|c|c|c|}
\hline Insect & Author & Date & Ref & Sys & Delivery & Cells & Gene & Mut & Results \\
\hline \multicolumn{10}{|l|}{ Orthoptera } \\
\hline Gryllus bimaculatus & Watanabe & 2012 & 15 & $\mathrm{Z}, \mathrm{T}$ & mRNA & $S, G$ & EGFP, Gb laccase2 & KO & $\begin{array}{l}\text { Z:48\%S; T:17\%S } \\
\text { Z:48\%G; T:17\%G }\end{array}$ \\
\hline \multicolumn{10}{|l|}{ Coleoptera } \\
\hline Tribolium castaneum & Gilles & 2015 & 63 & C & plasmid,mRNA,gRNA, & S, G & $E G F P$ & $\mathrm{KO}, \mathrm{KI}$ & $\begin{array}{l}62 \%-80 \% \text { S KO } \\
71 \%-100 \% \text { G KO } \\
17 \% \text { SI } \\
7 \% \text { KI }\end{array}$ \\
\hline \multicolumn{10}{|l|}{ Diptera } \\
\hline \multirow[t]{7}{*}{ Aedes aegypti } & Aryan & 2013 & 27 & $\mathrm{~T}$ & plasmid & $S, G$ & Aa-kmo, plasmid & KO & $\begin{array}{l}17 \%-66 \% G \\
1 \%-9 \% G 1\end{array}$ \\
\hline & DeGennaro & 2013 & 17 & Z & mRNA & G & EGFP, orco & KO & $2 \% \mathrm{G}$ \\
\hline & Liesch & 2013 & 18 & Z & mRNA & G & Aa-npylr1 & KO KI & $\begin{array}{l}28.6 \% \mathrm{G} \mathrm{KO} \\
0.09 \% \mathrm{G} \mathrm{KI}\end{array}$ \\
\hline & McMeniman & 2014 & 22 & Z & mRNA & G & AaGr3 & KO KI & $\begin{array}{c}43.8 \% \mathrm{G} \mathrm{KO} \\
0.49 \% \mathrm{G} \mathrm{KI}\end{array}$ \\
\hline & Basu & 2015 & 35 & $\mathrm{~T}, \mathrm{C}$ & mRNA,protein & $S, G$ & Aa-kmo, ligIV, ku70, r2d2, loqs & KO & $23 \%-90 \% G$ \\
\hline & Dong & 2015 & 61 & $\mathrm{C}$ & mRNA, plasmid & G & $E C G P$ & KO & 0\%-5.5\%G \\
\hline & Kistler & 2015 & 64 & C & plasmid,mRNA, protein & $S, G$ & $\begin{array}{c}\text { Aa-wtrw; AAEL000528; } \\
\text { AAEL010779; AAEL004091; } \\
\text { AAEL014228; AAEL000926; } \\
\text { AAEL002575; AAEL013647 }\end{array}$ & KO KI & $\begin{array}{l}0 \%-38 \% \mathrm{G} \mathrm{KO} \\
18.7 \%-21.4 \% \mathrm{G} 1 \mathrm{KO} \\
0.6 \% \mathrm{G} \mathrm{KI}\end{array}$ \\
\hline Anopheles gambiae & Smidler & 2013 & 28 & T & transgene & G & $A g-T E P 1$ & KO & $2.58 \%-51 \% \mathrm{G} 1$ \\
\hline \multirow[t]{3}{*}{ D. melanogaster } & Bibikova & 2002 & 11 & Z & transgene & $S, G$ & yellow & KO & $\begin{array}{l}46 \% \mathrm{~S} ; 5.7 \% \mathrm{G} \\
0.44 \% \mathrm{G} 1\end{array}$ \\
\hline & Beumer & 2006 & 12 & $\mathrm{Z}$ & transgene & $S, G$ & brown, rosy, yellow & KO KI & $\begin{array}{l}1-14 \% \mathrm{G} 1 \mathrm{KO} \\
1.5 \%-14 \% \mathrm{G} 1 \mathrm{KI}\end{array}$ \\
\hline & Beumer & 2008 & 13 & $\mathrm{Z}$ & mRNA & G & ry, coil, pask & KO & $\begin{array}{l}20 \%-46 \% G \\
8 \%-99 \% G 1\end{array}$ \\
\hline \multicolumn{10}{|c|}{$\begin{array}{l}\text { Ref-Reference } \\
\text { Sys- Endonuclease System: Z-ZFN; T-TALEN, C-Cas9, } C^{n} \text {-Cas9 with single-strand endonuclease activity (nickase), dC-dead Cas9 (no endonuclease activity) } \\
\text { Delivery: } m R N A \text {-injected in vitro transcribed message RNA; gRNA-injected in vitro transcribed guide RNA; plasmid-transient expression of system components from injected } \\
\text { plasmids; transgene-integrated transgenes containing system components; protein-purified Cas9 } \\
\text { Cells: } S \text {-somatic; G-germ-line; G1-progeny from } G \\
\text { Mut-Mutation: } K O \text {-knockout; KI-knockin, TA-transcription activation } \\
\text { NR-Not Reported }\end{array}$} \\
\hline
\end{tabular}




\begin{tabular}{|c|c|c|c|c|c|c|c|c|c|}
\hline Insect & Author & Date & Ref & Sys & Delivery & Cells & Gene & Mut & Results \\
\hline \multicolumn{10}{|c|}{$\begin{array}{l}\text { D. melanogaster - } \\
\text { continued }\end{array}$} \\
\hline & Baena-Lopez & 2013 & 39 & C & plasmid & G & dredd, wingless & $\mathrm{KI}$ & $0.2 \%-0.03 \% \mathrm{G} 1$ \\
\hline & Bassett & 2013 & 40 & C & mRNA & $\mathrm{S}, \mathrm{G}$ & white, yellow & KO & $\begin{array}{l}86 \% \mathrm{~S} \\
79 \% \mathrm{G}\end{array}$ \\
\hline & Beumer & 2013 & 16 & Z & mRNA & $\mathrm{G}$ & rosy & $\mathrm{KI}$ & $20 \%-60 \% \mathrm{G} 1$ \\
\hline & Gratz & 2013 & 41 & C & mRNA & $S, G$ & rosy, yellow & KO KI & $\begin{array}{l}5 \%-100 \% \mathrm{G} \mathrm{KO} \\
22 \% \mathrm{G} \mathrm{KI}\end{array}$ \\
\hline & Gratz & 2013 & 42 & C & plasmid & G & rosy & $\mathrm{KO} \mathrm{KI}$ & $\begin{array}{l}8 \%-27 \% \text { G KO } \\
1.4-22 \% G 1 \text { KO }\end{array}$ \\
\hline & Kondo & 2013 & 43 & C & transgene & G & $\begin{array}{l}\text { Ast, capa, Ccap, Crz, Eh, Mip, } \\
\text { npf, mir-219, mir-315, white }\end{array}$ & KO & $4-97 \% G$ \\
\hline & Ren & 2013 & 44 & C & transgene,plasmid & G & white & KO & $\begin{array}{l}23 \%-100 \% \mathrm{G} \\
0.6 \%-43 \% \mathrm{G} 1\end{array}$ \\
\hline & Yu & 2013 & 45 & C & mRNA,gRNA & $S, G$ & yellow & KO & $\begin{array}{l}35.7 \%-80 \% \mathrm{~S} \\
29.4 \%-68.2 \% \mathrm{G} \\
7.2 \%-12.6 \% \mathrm{G} 1\end{array}$ \\
\hline & Bottcher & 2014 & 47 & C & plasmid & S & phosphoglycerate kinase & KO & NR \\
\hline & Gokcezade & 2014 & 48 & C & transgene,plasmid & G & ebony, yellow, white & $\mathrm{KO} \mathrm{KI}$ & $\begin{array}{l}66 \% \mathrm{G} \mathrm{KO} \\
13 \% \mathrm{G} 1 \mathrm{KO} \\
2.6-8.6 \% \mathrm{G} 1 \mathrm{KI}\end{array}$ \\
\hline & Gratz & 2014 & 49 & C & plasmid,transgene,sgRNA & G & sosy, DSH3PX1 & KO KI & $\begin{array}{l}27 \%-53 \% \text { G KO } \\
20 \%-42 \% \text { G1 KO } \\
3 \%-18 \% \text { KI }\end{array}$ \\
\hline & Kondo & 2014 & 32 & $\mathrm{~T}$ & mRNA & & trachealess & KO & $\begin{array}{l}17 \%-39 \% \mathrm{G} \\
1.7 \%-32 \% \mathrm{G} 1\end{array}$ \\
\hline & Port & 2014 & 52 & C & transgene & $S, G$ & ebony, yellow, wingless, wnt & KO KI & $\begin{array}{l}100 \% \text { S KO } \\
70 \% \text { G1 KO } \\
11 \%-18 \% \text { G1 KI }\end{array}$ \\
\hline \multicolumn{10}{|c|}{$\begin{array}{l}\text { Ref-Reference } \\
\text { Sys- Endonuclease System: Z-ZFN; T-TALEN, C-Cas9, } C^{n} \text {-Cas9 with single-strand endonuclease activity (nickase), dC-dead Cas9 (no endonuclease activity) } \\
\text { Delivery: } m R N A \text {-injected in vitro transcribed message RNA; } g R N A \text {-injected in vitro transcribed guide RNA; plasmid-transient expression of system components from injected } \\
\text { plasmids; transgene-integrated transgenes containing system components; protein-purified Cas9 } \\
\text { Cells S-somatic; G-germ-line; G1-progeny from } G \\
\text { Mut-Mutation: KO-knockout; KI-knockin, TA-transcription activation } \\
\text { NR-Not Reported }\end{array}$} \\
\hline
\end{tabular}




\begin{tabular}{|c|c|c|c|c|c|c|c|c|c|}
\hline Insect & Author & Date & Ref & Sys & Delivery & Cells & Gene & Mut & Results \\
\hline \multicolumn{10}{|l|}{$\begin{array}{l}\text { D. melanogaster- } \\
\text { continued }\end{array}$} \\
\hline & Port & 2014 & 52 & C & transgene & $S, G$ & ebony, yellow, wingless, wnt & $\begin{array}{l}\mathrm{KO} \\
\mathrm{KI}\end{array}$ & $\begin{array}{l}100 \% \text { S KO } \\
70 \% \text { G1 KO } \\
11 \%-18 \% \text { G1 KI }\end{array}$ \\
\hline & Ren & 2014 & 54 & $C, C^{n}$ & transgene, plasmid & G & white, piwi & $\begin{array}{l}\mathrm{KO} \\
\mathrm{KI}\end{array}$ & $\begin{array}{l}\text { 18\%-81\%G KO(Cas9) } \\
<0.1 \% G \text { KO(dCas9) } \\
66 \% G \text { KI(Cas9) } \\
12.5 \% G \text { KI(dCas9) }\end{array}$ \\
\hline & Ren & 2014 & 53 & C & transgene, plasmid & G & ebony, vermillion, yellow & $\begin{array}{l}\mathrm{KO} \\
\mathrm{KI}\end{array}$ & $\begin{array}{l}12 \% \mathrm{G} \mathrm{KI} \\
11 \% \mathrm{G} 1 \mathrm{KI}\end{array}$ \\
\hline & Sebo & 2014 & 55 & C & transgene, plasmid & G & eGFP/RFP transgenes & KO & $\begin{array}{l}31 \%-71 \% \mathrm{G} \\
7.7 \%-24.7 \% \mathrm{G} 1\end{array}$ \\
\hline & Xue & 2014 & 57 & C & plasmid,transgene,gRNA & $S, G$ & ms(3)k81, white, yellow & $\begin{array}{l}\mathrm{KO} \\
\mathrm{KI}\end{array}$ & $\begin{array}{l}70 \%-100 \% \mathrm{~S} \text { KO } \\
4.5 \% \mathrm{G} 1 \mathrm{KO} \\
4.5 \% \mathrm{G} \mathrm{KI}\end{array}$ \\
\hline & Xue & 2014 & 58 & C & transgene & $\mathrm{s}$ & Notch, cid, ms(3)k81, yellow & KO & NR \\
\hline & Zhang & 2014 & 59 & C & transgene,gRNA & G & salm & $\mathrm{KI}$ & $1.8 \%-14.1 \% \mathrm{G}$ \\
\hline & Gantz & 2015 & 62 & C & transgene & G & yellow & $\mathrm{KI}$ & $95 \%-100 \% G$ \\
\hline & Lee & 2015 & 36 & $T$ & mRNA & $S, G$ & ebony, white & KO & $0.05 \%-89 \% \mathrm{G} 1$ \\
\hline & Port & 2015 & 65 & C & transgene & G & white & $\begin{array}{l}\mathrm{KO} \\
\mathrm{KI}\end{array}$ & $\begin{array}{l}0.5 \%-49 \% \mathrm{G} \mathrm{KO} \\
19 \%-88 \% \mathrm{G} \mathrm{KI} \\
3 \%-25 \% \mathrm{G} 1 \mathrm{KI}\end{array}$ \\
\hline & Lin & 2015 & 68 & $\mathrm{dC}$ & transgene & G & wingless & TA & mis-expression \\
\hline \multirow[t]{5}{*}{ Review Articles } & Gratz & 2013 & 42 & C & & & & & \\
\hline & Bassett & 2014 & 46 & C & & & & & \\
\hline & Daimon & 2014 & 20 & $\mathrm{Z}, \mathrm{T}, \mathrm{C}$ & & & & & \\
\hline & Kondo & 2014 & 32 & C & & & & & \\
\hline & Lin & 2014 & 50 & $\mathrm{Z}, \mathrm{T}, \mathrm{C}$ & & & & & \\
\hline \multicolumn{10}{|c|}{$\begin{array}{l}\text { Ref-Reference } \\
\text { Sys- Endonuclease System: Z-ZFN; T-TALEN, C-Cas9, } C^{n} \text {-Cas9 with single-strand endonuclease activity (nickase), dC-dead Cas9 (no endonuclease activity) } \\
\text { Delivery: } m R N A \text {-injected in vitro transcribed message RNA; gRNA-injected in vitro transcribed guide RNA; plasmid-transient expression of system components from injected } \\
\text { plasmids; transgene-integrated transgenes containing system components; protein-purified Cas9 } \\
\text { Cells S-somatic; G-germ-line; G1-progeny from } G \\
\text { Mut-Mutation: } K O \text {-knockout; } K I \text {-knockin, } T A \text {-transcription activation } \\
\text { NR-Not Reported }\end{array}$} \\
\hline
\end{tabular}

